\title{
Erratum to: Effect of hole size on fluid dynamics of a posterior-chamber phakic intraocular lens with a central perforation by using computational fluid dynamics
}

\author{
Takushi Kawamorita $^{1} \cdot$ Kimiya Shimizu $^{2} \cdot$ Nobuyuki Shoji $^{1}$
}

Published online: 1 March 2016

(C) Springer-Verlag Berlin Heidelberg 2016

Erratum to: Graefes Arch Clin Exp Ophthalmol

DOI 10.1007/s00417-016-3304-3

The original version of this article inadvertently contained a mistake.

Reason: Table 1 not correctly pictured

Table 1 Parameters of eye model

\begin{tabular}{ll}
\hline Corneal thickness & $0.5 \mathrm{~mm}$ \\
Posterior corneal surface - iris plane & $2.1 \mathrm{~mm}$ \\
Iris thickness & $0.5 \mathrm{~mm}$ \\
ICL vaulting & $0.5 \mathrm{~mm}$ \\
Gap between iris and ICL & $0.05 \mathrm{~mm}$ \\
Iridocorneal angle & $33.0 \mathrm{deg}$
\end{tabular}

The online version of the original article can be found http://dx.doi.org/ 10.1007/s00417-016-3304-3.

Takushi Kawamorita

kawa2008@kitasato-u.ac.jp

1 Department of Orthoptics and Visual Science, Kitasato University School of Allied Health Sciences, 1-15-1 Kitasato, Minami-ku, Sagamihara City, Kanagawa, Japan 252-0373

2 Department of Ophthalmology, Kitasato University School of Medicine, Sagamihara City, Kanagawa, Japan 